\title{
Evaluating the Comparative Values of Lipid Profile among Premenopausal and Postmenopausal Women
}

\author{
Muhammad Ahmed Alamgir ${ }^{1, *}$, Ishfaq Ahmed ${ }^{2}$, Hashim Raza ${ }^{1}$, Faridudin ${ }^{2}$ \\ ${ }^{1}$ Bahawal Victoria Hospital, Quaid-e-Azam Medical College, Bahawalpur, Pakistan \\ ${ }^{2}$ Senior Registrar Medicine, Civil Hospital Bahawalpur, Pakistan \\ *Corresponding Author: alamgirkhan916@yahoo.com
}

Copyright $\odot 2017$ by authors, all rights reserved. Authors agree that this article remains permanently open access under the terms of the Creative Commons Attribution License 4.0 International License

\begin{abstract}
Objectives: The study aims at comparing the changes of serum lipid levels in premenopausal women with that of postmenopausal counterparts. Study Design: An observational comparative and prospective study. Subjects and Method: One hundred healthy subjects (fifty each pre and postmenopausal women) between ages from 25 to 65 years, were selected for the study. They were nonsmoker, non-addict and not user of any hormonal contraceptive. The subjects were arranged in two age ranges of $25-45$ years (group A) and $45-65$ years of age (group B) .The quantitative data was collected and applied accordingly. The fasting serum lipids samples consisting of total cholesterol (TC), high density lipoproteins (HDL-C), and triglyceride (TG) were estimated calorimetrically using the enzymatic method. NCEP ATPIII criterion was used to determine their values in normal or high risk category. According to their recommendations, in healthy females, total cholesterol should be $<200 \mathrm{mg} / \mathrm{dl}$.The quantitative variables were displayed as mean \pm standard deviation and percentage. The statistical difference for lipoproteins at 5\% significance level was assessed by applying one sample " $\mathrm{t}$ " test. Results: In subjects of group A, the mean total cholesterol and HDL-C levels were $158.14 \pm 28.77 \mathrm{mg} / \mathrm{dl}$ and $38.98 \pm 8.48 \mathrm{mg} / \mathrm{dl}$ respectively. Triglycerides level was $142.24 \pm 88.387 \mathrm{mg} / \mathrm{dl}$ and within normal range. In females with age group $\mathrm{B}$, the mean concentration of total cholesterol and HDL-C were $210.74 \pm 59.156 \mathrm{mg} / \mathrm{dl}, \quad 32.94 \pm 7.582 . \mathrm{mg} / \mathrm{dl}$ respectively. Triglycerides level was $160.68 \pm 68.131 \mathrm{mg} / \mathrm{dl}$. So in subjects of group B, all lipid values were in high risk category when compared to cut off values determined by NCEP/AHA. Conclusion: Menopause leads to changes in lipid profile by reducing HDL, and elevating total cholesterol (TC), and triglycerides (TG), thus increasing the risk for cardiovascular events.
\end{abstract}

Keywords Lipid Profile, Premenopausal, Postmenopausal Women

\section{Introduction}

According to WHO estimates, 16.7 million people around the globe die of cardiovascular diseases each year -- among them 8.6 million are women [1] .Contemporarily $86 \%$ of global burden of cardiovascular diseases are in developing countries including Pakistan [2, 3]. Coronary heart diseases and stroke cause 1 in 3 women's deaths each year, killing approximately one woman every 80 seconds. It is estimated that in United States one in every two women die of a heart related disorders, which represents more deaths than due to cancer, chronic lung conditions, and accidents combined [4]. These devastating consequences may be prevented by lifestyle changes and education. The medical literature suggests that ovarian hormones like estrogen can protect vascular endothelium, reduce blood fats and help prevent clotting $[5,6,7]$.This lipid lowering with cardio protective effects during reproductive age, are lost after menopause and ultimately account for more than $50 \%$ of all deaths in women over 50 years of age $[8,9,10]$.

This panorama is more obvious by considering the fact that central pathological mechanism leading to these complications is atherosclerosis and it is rapidly accelerated due to hyperlipidemia. According to international guidelines hyperlipidaemia is defined as elevations of fasting total cholesterol concentration or reduced HDL levels which may or may not be associated with elevated Triglycerides concentration [11]. There is strong association between raised total cholesterol and coronary heart diseases while higher HDL concentration is considered to be cardio protective. Meta-analysis of large randomized trials concluded that $45 \%$ of deaths from CHD in men and more than $47 \%$ in women are due to hypercholesterolemia $[12,13]$. It is evident that dyslipidemia or atherogenic lipoprotein index in women is unique and characterized by increase in total cholesterol or decrease in HDL and each being independently atherogenic [14.15].

Large population studies, expertly steered by researchers, revealed that in women HDL-C was strong predictors of 
CVD than total cholesterol and women who had HDL-C levels less than $50 \mathrm{mg} / \mathrm{dl}$ had a $30 \%$ increased risk for cardiovascular mortality. Because HDL has more cardio protective effect in females as compared with males. [16, 17, 18]. Hence there is scientific and logical reason that lipid lowering drugs or preventive life style interventions are beneficial in midlife women. Evidence based medicine we all allude to practice is research based and needs adherence to designed guideline. So considering the USPSTF recommendations, there is a general consensus to screen women aged 45 and older for lipid disorders if they are at increased risk for coronary heart disease [19]. In Pakistan, authorities also promote screening based strategies and bringing about an improvement in health outcome [20].

Our concept is thought provoking and innovative. Previously no research data exists to compare the components of lipid profile in women of south Punjab on above mentioned subject. The present study did not aimed to assess other risk factors but it focused to explore the level of lipids among women and to compare with cut off values already known internationally.

\section{Aims and Objectives}

To evaluate the comparative values of total cholesterol, HDL-C, and triglyceride (TG) between premenopausal and postmenopausal women.

To calculate the TC: HDL ratio among above mentioned subjects

\section{Materials and Methods}

This comparative and observational work was carried out in medical outdoor department, BVH Bahawalpur, during period from 1.1.2016 to 30.6.2016. One hundred apparently healthy females, 50 premenopausal (aged between 25-45 years) and 50 postmenopausal (aged between 45-65 years) were recruited for study after having formal consent.

Exclusion criteria: The subjects with hypertension, diabetes mellitus, hepatic disease, having lipid lowering drugs and those with obesity or overweight, were excluded from study. In the evaluation, the investigators had detail clinical history including current drug use and recording of gynecological events.
Anthropometric measurements were obtained by measurements of weight and height in light clothing. Body mass index (BMI) was calculated by dividing weight in $\mathrm{kg}$ by height in meters (square). Normal BMI ranges from 18 to 24. Fasting samples of total cholesterol, triglycerides, and HDL levels were taken and centrifuged within 15-minutes.Their laboratory values were determined by ELIZA (Rendox Labs). These collected data was analyzed through computer software SPSS version 11. Current classification schemes for hyperlipidaemia, based on National Cholesterol Education Panel (ATP III), were used to consider the normal cut off values of lipoproteins as ready reckoner because these are internationally agreed upon [21, 22]. According to their recommendations, in healthy females, total cholesterol should be $<200 \mathrm{mg} / \mathrm{dl}$.

They suggest that HDL-C levels less than $50 \mathrm{mg} / \mathrm{dl}$ should be considered a CHD risk factor in women; this is $10 \mathrm{mg} / \mathrm{dl}$ higher than the recommended level for men. For HDL-C values in women high risk, border line and low risk were $<$ $40 \mathrm{mg} / \mathrm{dl}, 40-45 \mathrm{mg} / \mathrm{dl}$ and $>50 \mathrm{mg} / \mathrm{dl}$ respectively[12, 13]. It is noteworthy that TC: HDL ratio is a valuable tool to predict cardiovascular risk and acceptable ratio for men is 5 or below and for females it is 4.5 or below. [4, 11]

One sample ' $T$ ' test was applied for lipid levels and mean value of quantitative data were represented as mean SD. Their values were tested at $5 \%$ significance level and the $\mathrm{P}$ value $<0.05$ was considered as significant.

\section{Results}

The study population was divided into two complementary groups - Group A (25-45 years) and Group B (45 - 65 years).The remarkable data was obtained. The baseline demographic variables are shown in table-1: Both groups had equal height and weight and similar BMI.

Table 1. Demographic data of the subjects $(n=100)$

\begin{tabular}{|c|c|c|}
\hline $\begin{array}{c}\text { Demographic } \\
\text { indicators }\end{array}$ & $\begin{array}{c}\text { Premenopausal } \\
\text { (Group A) }\end{array}$ & $\begin{array}{c}\text { Postmenopausal } \\
\text { (Group B) }\end{array}$ \\
\hline Age & 25 to 45 years & Above 45 years \\
\hline Weight $(\mathrm{kg})$ & $53 \pm 10.14$ & $52 \pm 11.75$ \\
\hline Height $(\mathrm{m})$ & $1.651 \pm 0.127$ & $1.6 \pm 0.30$ \\
\hline BMI $\left(\mathrm{kg} / \mathrm{m}^{2}\right)$ & 19.44 & 20.31 \\
\hline
\end{tabular}

Table 2. Comparative values of Lipid profile among both groups

\begin{tabular}{|c|c|c|c|c|}
\hline Lipid Parameters & $\begin{array}{c}\text { Group A } \\
\text { (Premenopausal) }\end{array}$ & $\begin{array}{c}\text { Group B } \\
\text { (Postmenopausal) }\end{array}$ & T-test & P-value \\
\hline Serum cholesterol & $158.14 \pm 28.779$ & $210.74 \pm 59.156$ & 34.606 & $\mathrm{P}<0.001 \star$ \\
\hline Serum TGS & $142.24 \pm 88.387$ & $160.68 \pm 68.131$ & 19.158 & $\mathrm{P}<0.001 \star$ \\
\hline Serum HDLC & $38.98 \pm 8.484$ & $32.94 \pm 7.582 . \mathrm{mg} / \mathrm{dl}$ & 42.004 & $\mathrm{P}<0.001 \star$ \\
\hline $\begin{array}{c}\text { TC }: \text { HDL-C ratio } \\
\text { (normal }<5 \text { ) }\end{array}$ & 4.1 & 6.5 & & \\
\hline
\end{tabular}

=highly significant. 
The table no .2. has elaborated the data comprehensively. It shows the mean values of total cholesterol, HDL and triglycerides concentrations among both groups along with calculated TC: HDL-C ratio. It is noteworthy that its normal value should be $<5$ and it is useful tool to predict the risk of cardiovascular disease.

In the age group A (25-45 years.), the total cholesterol was $158.14 \pm 28.779$ and HDL-C was $42.004 \mathrm{mg} / \mathrm{dl}$ respectively. Triglycerides level was $142.24 \pm 88.387 \mathrm{mg} / \mathrm{dl}$. All these findings turned out to be within normal range.

For the age group B (45-65 years), the total cholesterol was $210.74 \pm 59.156 \mathrm{mg} / \mathrm{dl}$. $(\mathrm{P}<0.001)$ and HDL-C was $32.94 \pm 7.582 . \mathrm{mg} / \mathrm{dl}(\mathrm{P}<0.001)$ respectively. Both these values were raised and statistically highly significant. The values of triglycerides were $160.68 \pm 68.13 \mathrm{mg} / \mathrm{dl}$ (highly significant at $\mathrm{P}<0.001$ ).

The atherogenic index (TC/HDL ratio) was also significantly increased in post-menopausal women as well. Moreover, HDL-cholesterol/total cholesterol ratio could be a better marker of coronary heart disease and suggest the importance in subjects without risk factors for atherosclerotic disease.

\section{Discussion}

A number of valuable trials have suggested that in developed countries, postmenopausal women are four to eight times more likely to die of CAD than of cancer (including breast cancer), chronic lower respiratory disease, Alzheimer disease and accident combined[1,4]. Dyslipidaemia is the established surrogate marker of vascular risks. Elizabeth Cady Stone once said "the heyday of women life is Shadyside of fifty." So the chronology of their healthier midlife events can be skillfully depicted through crafted preventive measures of dyslipidaemia. The present study endeavors to investigate this paradigm. In these prospects we obtained the remarkable findings. Let us distinctly recall the international cut off values as determined by NCEP ATP III and AHA .They have recommended that HDL-C (good cholesterol) should be essentially more than $50 \mathrm{mg} / \mathrm{dl}$ for women and more than $35 \mathrm{mg} / \mathrm{dl}$ in men. While women who had HDL-C levels less than $50 \mathrm{mg} / \mathrm{dl}$ had a $30 \%$ increased risk for cardiovascular mortality, Total fasting cholesterol (bad cholesterol) should be below $200 \mathrm{mg} / \mathrm{dl}$, lower the cholesterol beneficial it is[21,22]. Moreover TGs should also be $\leq 150 \mathrm{mg} / \mathrm{dl}$ as well. All the above mentioned values were significantly raised in our female cohort of group B and were in high risk category when compared to cut off values determined by NCEP/AHA.

ATP III recognizes that risk for CHD is influenced by other factors not included among the major, independent risk factors Among these are life-habit risk factors and include obesity, physical inactivity, atherogenic diet, and evidence of subclinical atherosclerotic disease. The life-habit risk factors are direct targets for clinical intervention. Several research trials had correlated the relationship of dyslipidemia in midlife women. A Pakistani research work conducted by Faryal and Rashid et al [23] had shown the lipid values in reproductive age group. Their mean concentration of serum total cholesterol was $177.9 \pm 40.8$, and triglycerides were $129.1 \pm 27$. Serum HDL-C was $53.1 \mathrm{mg} / \mathrm{dl}$ and all values were within normal limits.

On comparison between women of reproductive age group and post-menopausal women with normal BMI, Rajesh k et al [24] has contributed to the better understanding of lipid profile status in postmenopausal group. They found that "the levels of TC $(200.74 \pm 79.27)$ and TG $(160.96 \pm 48.12)$ were significantly higher in post-menopausal women $(P<0031 * *)$. Although, HDL-C levels (37.8 $\pm 9.20 \mathrm{mg} \%)$ were significantly high risk category in this group as compared with premenopausal subjects $(P 0.0113 *)$. LDL-C levels were also significantly higher in later group comparatively $(P<0.001)$."

Pakisani authors Nazeer $M$ and Naveed $T$ et al [25], in their study population of 198 female subjects, have concluded that despite its high prevalence in total female (53\%) and premenopausal group (59\%) hyperlipidaemia did not reach statistical significance in these subgroups. It showed a statistically significant relationship in postmenopausal group only.

Analogous findings were observed by Bade S and SHAH $\mathrm{S}$ [26].They found that, "the levels of TC (246.62 \pm $29.19 \mathrm{mg} \%)$ and TG (131.22 $\pm 18.99 \mathrm{mg} \%)$ were significantly higher in post-menopausal women than those of pre-menopausal counterparts $(P<0.05)$. HDL-C levels were significantly lower (moderate risk category $P<0.001$ ) and LDL-C (224.21 $\pm 30.98 \mathrm{mg} \%)$ levels were also significantly higher in postmenopausal group. $(P<0.001)$ ". There is paucity of Pakistani studies on his subject and substantial data was not available.

Varu DS and Vegad DM [27] have shown the same observations. As compared to their reproductive age subjects, the mean level of serum total cholesterol $(14.97 \pm 0.99 \mathrm{~mm} / \mathrm{l})$ and serum LDL $(3.37 \pm 1.08 \mathrm{~mm} / 1)$ were significantly higher in postmenopausal women and level significantly increased with age.

Our results are also in conformity to Mallik M et al [28]. Their postmenopausal group had a statistically significant increased levels of TC $\left(211.67 \pm 21.35^{*}\right)$ LDL-C $(137.65 \pm$ $\left.21.03^{* *}\right)$ and significantly decreased HDL $\mathrm{C}$ when compared to those in reproductive phase. The serum TG levels, although increased in postmenopausal women, but statistically not significant.

Reddy Kilim S and Chandala SR [29] have reported approximately matching observation. Their study aimed to rediscover the influence of menopause on lipid profile in women. Among their pre and postmenopausal subjects, the mean values of TC was $153.38 \pm 17.44$ and $211.24 \pm$ $29.58 \mathrm{mg}$ ( $\mathrm{p}$ value $<0.001$ ) while HDL-C was $46.66 \pm 7.27$ and $27.7 \pm 5.6 \mathrm{mg}(\mathrm{p}$ value $<0.001)$ respectively. They suggested that after menopause, the risk of cardiovascular 
disease is due to established link of deranged lipids with atherosclerosis.

The results are not always same among different population groups. There are racial/ethnic differences in dyslipidemia and heterogeneity in CVD risk among subgroups. Most minority groups had increased prevalence of low HDL and high TGs except for Japanese and African Americans. The prevalence of high LDL-C was increased among Asian Indians, Filipinos, Japanese, and Vietnamese; there is a paucity of studies on dyslipidemia in South Asians.

South Asian has shown lower risk factors than the urban westernized. This may be due to physically active occupations and high fiber diet .Asians from India or Pakistan may have different CVD risk profiles compared with those from China or Japan. [30, 31]

Some contrary results were obtained in few research studies. Swarma $\mathrm{M}$ et al [32] revealed no significant difference in cholesterol and LDL but statistically significant difference were observed in triglycerides and HDL values. Hassan et al. [33] had concluded that biochemical parameters were mostly non-significant changed $(\mathrm{P}>0.05)$ while physical parameters were deviated significantly $(\mathrm{P}<0.001)$ when comparisons were made between mean values of various study groups.

Despite vernacular diversity of this research along with cosmopolitan quality, our work is limited by its cross-sectional nature; therefore, causal pathways underlying hormonal relationships cannot be inferred as this paper presents analyses of work done as part of routine lipoprotein analysis. William Osler once declared "The good physician treats the disease; the great physician treats the patient who has the disease". This encourages initiating the process for educating the public and devising local preventive measures and guidelines to effectively combat the risk factors along with devastating consequences.

\section{Conclusions}

The present study has dynamically concluded that menopause has established link with altered lipid levels. So it is legitimate that every middle aged women should opt for screening of lipids as preventive measure and its treatment accordingly.

\section{Disclosure of Interest}

This paper is submitted for academic purposes and we have no conflicts of interest to disclose

\section{Ethical Review Statement}

We do not have formal ethics review committees .The study protocol followed in accordance with the principles of Declaration of Helsinki.

\section{Acknowledgements}

The authors gratefully acknowledge the help of Dr. Irum Alamgir for collecting the data and writing the manuscript.

\section{REFERENCES}

[1] Bulletin of the World Health Organization 2013; 91: 630-639. http://dx.doi.org/10.2471/BLT.12.1097102

[2] F Aziz. Coronary Artery Disease in Women: An Unsolved Dilemma. Clint Med Res.2014Apr;6(2):86-90.doi:10.14740/ jocmr $1725 \mathrm{w}$

[3] Jafar TH, Qadri Z, Chaturvedi N. More electrocardiographic evidence of ischemic CV disease epidemic in Pakistan, in women than in men.Heart.2008; 94(4):408-413

[4] Mozaffarian D, Benjamin E, Go A, et al .Heart disease and stroke statistics-2016 update. Are port from the American Heart Association.Circulation.2016; 133:e38-360.

[5] Xin Liu,Chunyu Guo, Xiaojuan Ma, Rui Tian, Ying Zhang, Relationship between serum estrogen levels and blood stasis syndrome in postmenopausal women with coronary heart diseases. Pak JMedSci.2015Jan-Feb; 31(1): 25-30

[6] Estrogen and mechanisms of vascular protection. Xing D, Nozell S, Chen YF, Hage F, Arterioscler Thromb Vasc Biol.2009 Mar; 29(3): 289-95

[7] Hodis HN, Mack WJ, Henderson VW, et al. Vascular effects of early versus late postmenopausal treatment with estradiol. N Engl J Med 2016; 374: 1221-1231

[8] R.J. Baber, N. Panay \& A. Fenton the I MS Writing Group(2016)2016IMS Recommendations on women's midlife health and menopause hormone therapy, Climacteric, 19:2, 109-150, DOI:10.3109/13697137.2015.1129166

[9] Boardman HM, Hartley L, Eisinga A et al. Hormone therapy for preventing cardiovascular disease in post-menopausal women Cochrane Database Syst Rev2015;:CD002229

[10] Virginia M. Miller1 and JoAnnE. Manson Women's Health Initiative Trials: New insights on Cardiovascular Disease from Additional Years of Follow up. Cur Cardiovascular Risk Rep. 2013 Jun1; 7(3): 196-202 doi: 10.1007/s12170-01 0305-1.

[11] ACC/AHA Guideline on the Treatment of Blood Cholesterol to Reduce Atherosclerotic Cardiovascular Risk in Adults. Circulation.2014;129:S1-S45.doi:10.1161/01.cir.000043773 8.63853 .7

[12] (Cholesterol Treatment Trialists (CTT) Collaborators. The effect so flowering LDL cholesterol with statin therapy in people at low risk of vascular disease: meta-analysis of individual data from 27 randomized trials. Lancet.2012Aug11; 380(9841):581-90. [pmid:22607822]

[13] Anthony K et al. Efficacy and safety of LDL-lowering therapy among men and women: meta-analysis of individual data from 174000 participants in 27 randomized trials. The Lancet, January 2015 DOI: 10.1016/S0140-6736(14).61368-4 
[14] Binh An P Phan, Peter P Toth. Dyslipidemia in women: Int J Women'sHealth.2014; 6:185-194. Published on line 2014 February7. doi: 10.2147/IJWH. S38PMC3923614

[15] Mora S., Glynn RJ., Hsia J, et al. Statins for the primary prevention of cardio vascular events in women with elevated high-sensitivity C-reactive protein or dyslipidemia: Results from the Justification for the Use of Statins in Prevention: An Intervention Trial Evaluating Rosuvastatin (JUPITER) and meta-analysis of women from primary prevention trials. Circulation 2010; 121: 1069-1077 [PMC free article] [PubMed]

[16] K Mahdy Ali, A Wonnerth, K Huber, Cardiovascular disease risk reduction by raising HDL cholesterol-current therapies and future opportunity. Br J Pharmacol. 2012 Nov; 167(6): 1177-1194.doi: 10.1111/j.1476-5381.2012.02081.

[17] Cooney MT. Score investigators. HDL protect against CHD. Atherosclerosis 20092006(2). 606. 11

[18] Alwallik. High density lipoprotein cholesterol and CV diseases. 2010. An update. Expert Rev Cardiovasc. 2010. (3). 413.23.

[19] U.S Preventive Services Task Force. Screening for lipid disorders in adults. Recommendations statement http://www.uspreventiveservicestaskforce.org/uspstf08/lipid/ lipidrs.htm)

[20] Planning Process: National Action Plan for Prevention and Control of Non-Communicable Diseases and Health Promotion in Pakistan; Heartfile. http://heartfile.org/napproc ess.htm (accessedApr 12, 04).

[21] National Institute of Health. Third report of NCEPATPIII. AssessedDec2013(www.nih.gov/guidlines/cholesterol/at/full

[22] Stone, N.J., Robinson, J., Lichtenstein, A. H. et al, ACC/AHA guideline on the treatment of blood cholesterol to reduce atherosclerotic cardiovascular risk in adults. A report of the ACC/AHA Task Force on Practice Guidelines. Circulation. November122013DOI:http://dx.doi.1161/01.cir.0000437738 $.63853 .7 \mathrm{a}$.

[23] (Faryal U, Rashid S, Hajra B. Lipid profile in females of reproductive age group using combined oral contraceptive pills GomelJMedSci2012;10:233-6)
[24] Rajesh K Jambhulkar, Trupti Ramteke, Ashish Anjankar, Pankaj Kamble. Comparison of lipid profile in pre and postmenopausal women. Inter J Sciand Tech April 2015; 14(3): 631-635http://www.statperson.com (accessed 25 April 2015).

[25] Nazeer M., Naveed, T. Ullah, A. A case control study of risk factors for CHD in Pakistani females Annals of KEMU(Print); v.16(3); ISSN2079-7192; Jul-Sep2010; p.162-168)

[26] Bade G, Shah S, Nahar P, Vaidya S. Effect of menopause on lipid profile in relation to body mass index. Chron Young Sci [serial online] 2014 [cited 2015, DOI: 10.4103/2229-5186.1 29331

[27] Varu DS, Vegad DM, Jani DHA, Savalia DV, Joshi DS. A comparative study of Serum lipid Profile between premenopausal And Postmenopausal Women. NJIRM. (2012), [cited June 26, 2015; 3(1): 43-45')

[28] Mallick AK, Ahsan M, Das B, Saxena S, Samanta S, Kukreja S Study of lipid profile during menopause in North Indian women, late reproductive phase and perimenopause. Inter J of med Res. January-February, 2015/Vol3/Issue1 ISSN2321-12 $7 \mathrm{X})$

[29] Reddy Kilim S1, chandala SR. A comparative study of lipid profile and oestradiol in pre and postmenopausal women J Clint Diagn Res. 2013 Aug; 7(8): 1596 doi:10.7860/JCDR/ 2013/6162.3234

[30] Ariel THF rank, Beinan Zhao, Powell O. Jose, Kristen MJ Azar, Stephen PF ortmann, Racial/Ethnic Differences in Dyslipidemia Patterns. PMC 2014 Oct. 29 Circulation. 2014 Feb. 4; 129(5): 570-579. Published online 2013 Nov5 doi:10.1161/CIRCULATIONAHA.113.00575

[31] Centers for Disease Control and Prevention NCfHS. [AccessedApril11, 2013]; National Health and Examination Survey: Noteon2007-2010 Sampling Methodology. 2011 http://www.cdc.gov/nchs/nhanes/nhanes2007-2008/sampling

[32] Swarna M. Vandana G.A comparative study of lipid profile between pre and post-menopausal women JDMedSci. April, 14(4), p,5153 Doi.10.9790/0853..14485153,

[33] Hussain Z, Akram M, Nadeem M, Masood S, Ahmad F, Ahmad A. Post-menopausal women; atherosclerotic risk factors. ProfessionalMedJJul-Sep2007; 14(3):484-90. 